\title{
La lucha antifascista: hacia la politización reformista de la clase obrera. El caso entrerriano, 1931-1943
}

\section{The anti-fascist struggle: towards the reformist politicization of the working class. The entrerriano case, 1931-1943}

\author{
Rodolfo Leyes \\ Universidad Autónoma de Entre Ríos, \\ Consejo Nacional de Investigaciones Científicas y Técnicas (Argentina) \\ rodolfoleyes@yahoo.com.ar
}

\section{Resumen}

El presente trabajo trata las transformaciones políticas que vivieron el movimiento obrero y la izquierda en la provincia de Entre Ríos entre los años 1931-1943. Durante el periodo de estudio encontramos una serie de luchas que llevaron a cabo dichas fuerzas contra el avance del fascismo que, según los contemporáneos, se desarrollaba en todo el país.

Sin embargo, la intervención contra las fuerzas fascistas concretó una alianza con sectores progresistas de los partidos burgueses, en especial, con los radicales en el poder. De la mano de la alianza para construir un frente popular antifascista, mostramos cómo los partidos y los gremios fueron morigerando el discurso clasista y revolucionario en sus demandas y como la democracia burguesa va ocupando un lugar destacado en el discurso y la acción de lucha.

Proponemos que el movimiento obrero entrerriano y los partidos de izquierdas, en la lucha antifascista, produjeron el desarrollo del reformismo obrero.

\section{Palabras Clave}

Movimiento obrero; Partidos de izquierdas; Antifascismo; Reformismo obrero; Entre Ríos

\begin{abstract}
The present work deals with the political transformations that the labor movement and the left lived in the province of Entre Ríos between the years 1931-1943. During the period of study we find a series of struggles carried out by these forces against the advance of fascism that, according to contemporaries, developed throughout the country.

However, the intervention against the fascist forces made an alliance with progressive sectors of the bourgeois parties, especially with the radicals in government. From the hand of the alliance to build a popular anti-fascist front, we show how the parties and the unions were moderating the classist and revolutionary discourse in their demands and how bourgeois democracy is occupying a prominent place in the discourse and action of struggle. We propose that the workers movement from Entre Ríos and the left parties, in the antifascist struggle, they produced the development of worker reformism.
\end{abstract}

Keywords

Workers movement; Left parties; Antifascism; Workers reform; Entre Ríos

Esta obra está sujeta a la Licencia Reconocimiento-NoComercial-CompartirIgual 4.0 Internacional de Creative Commons. http://creativecommons.org/licenses/by-nc-sa/4.0/ 


\section{La lucha antifascista: hacia la politización reformista de la clase obrera. El caso entrerriano, 1931-1943.}

\section{Introducción}

La década del treinta fue una década de crisis. Los cambios alcanzaron todos los aspectos de la vida social, que poco a poco se acomodaron al nuevo contexto. Entre Ríos no escapó a estas transformaciones. Los límites del desarrollo expansivo y los buenos precios agrarios de los años veinte sirvieron para continuar un desarrollo capitalista en profundidad pero, como correlato social por la creciente desocupación, los obreros buscaron refugio en las ciudades. Por otra parte, la industria sustitutiva acrecentó el tamaño del proletariado fabril que se unificó en torno a sindicatos de ramas de industria sustituyendo los sindicatos por oficios. En el ámbito político, la crisis precipitó la caída de Yrigoyen e inauguró la era de golpes militares. Una oleada de derecha que admiraba los regímenes corporativistas y reaccionarios de Europa se alzó en Argentina (Deutsch y Dolkart, 2001). Al golpe de Estado le siguió la proscripción a la UCR. Pero también la represión estatal a los disidentes políticos y sindicales.

El surgimiento del fascismo fue un punto de inflexión para la izquierda y los sectores progresistas. En efecto, gobiernos capitalistas, nacionalistas, estatistas que reclamaban la subordinación a la ley -inclusive la Ley Marcial- con un peso central en la tradición religiosa, hicieron de los fascistas el enemigo ideal para la izquierda en sus variantes. La lucha antifascista contra un enemigo que se combatía a nivel mundial hacía más épico el enfrentamiento(Hobsbawm, 2005). En este sentido la lucha contra el enemigo común produjo fuertes cambios de estrategias y reconfiguración de las alianzas político-sociales.

Si bien la llegada de exiliados con noticias sobre las políticas represivas de los fascistas italianos y de los nazis alemanes era conocida, fue el golpe de Estado de 1930 lo que precipitó la lucha antifascista. Los desfiles de la Legión Cívica agrupamiento de extrema derecha- no dejaban lugar a dudas de su similitud con los desfiles de los camisas pardas nazis. La cárcel de Ushuaia, llena de opositores políticos recordaban las cárceles italianas, la represión permanente sobre el movimiento obrero, la clausura de sindicatos, de escuelas obreras judías e incluso el fusilamiento del anarquista Severino Di Giovanni, fueron algunos de los hechos que mayor repercusión tuvieron en los primeros años de la década, agravado luego, por las noticias de la Guerra civil española y la Segunda Guerra mundial que amplificaron las posiciones con la llegada de nuevos contingentes de exiliados (Montenegro,2006; Romero, 2011; Iñigo Carrera, 2006).

La década del treinta para la provincia de Entre Ríos tuvo marcas particulares. Por un lado vemos que la crisis golpeó fuerte en la economía agraria. El agro-pampeano sufrió no solo los embates de las retracciones de los mercados, sino también de las pérdidas de las cosechas (campañas 1932-1933 y 1939-1940) (Biasizo, 2008). Estas contracciones, sumadas a la creciente mecanización de las tareas agrarias y de las industrias asociadas, afectaron fuertemente la contratación de la mano de obra, lo 


\section{Rodolfo Leyes}

que generó la formación temprana de una sobrepoblación obrera que no encontraría trabajo. Carente de una industria sustitutiva que absorbiera a los obreros desocupados, la migración fue la salida más rápida y efectiva del estado de miseria (Leyes, 2018).

En el ámbito político, la provincia no fue intervenida por el Poder Ejecutivo nacional durante toda la década, permitiendo cierto relajamiento en la vida política y gremial, y los actores pudieron continuar sus prácticas políticas normalmente. En particular para los miembros de la Unión Cívica Radical, pertenecientes al ala antipersonalista, que continuaron en el gobierno. En este marco político y económico la provincia de Entre Ríos desarrolló un movimiento antifascista que creció durante aquellos años denunciando no solo las situaciones extra-provinciales, sino también el accionar de las fuerzas endógenas que se desarrollaban en la provincia (Argachá, y Busiello, 2013; McGee Deutsch, 2003).

La historiografía captó la reacción de los grupos antifascistas en Argentina. Si bien aún no contamos con una obra que sintetice los aportes hasta el momento, existen dos de tipos explicaciones: las que presentan la reacción antifascista como continuidad de la tradición liberal con una mirada teleológica hasta el peronismo y aquella que reflejó la relación entre el surgimiento del fascismo y el movimiento obrero.

En el primer grupo tenemos los trabajos de José Luis Romero (1956), Gino Germani (1962) y Tulio Halperín Donghi (2006). Las obras de los autores tienen en común la denuncia del fascismo en los treinta y son apologéticas en tono anti-peronista, denunciaban el riesgo del fascismo y cómo con ciertos matices según la autoría el peronismo vino a ser una variante nacional de aquel movimiento (Romero 2011, Sebastiani 2006). Y encontró una profundización en los trabajos de Andrés Bisso, quien estudió el antifascismo en dos trabajos. El primero aborda la Acción Argentina (Bisso 2005), una alianza entre liberales y socialistas que formó el "espectro antifascista liberal-socialista", dónde Bisso da cuenta de la participación de los miembros del Partido Socialista (PS), Radical y otros menores que buscó romper los posicionamientos neutralistas de la política exterior argentina a favor de las fuerzas aliadas y reivindicando la diversidad social y religiosa, esta posición trazó una línea de continuidad con la tradición liberal argentina y presentó a los fascistas como antinacionales.

La segunda obra de Bisso (2007) fue El antifascismo argentino, presenta una compilación de documentos seleccionados del antifascismo argentino de los años 1922-1946 y tiene diálogo final con el peronismo. La compilación cuenta con un estudio realizado por el autor que busca mostrar la variedad de formas del discurso antifascista. Ese es su principal aporte y también su límite. Habida cuenta de la falta de trabajos específicos, delinear los márgenes del discurso nos facilita acercarnos a un objeto nombrado pero desconocido, no obstante, conocer lo que se decía no nos permite estar al tanto del desarrollo real de la fuerza antifascista.

Tal como dijimos, existe otro grupo de trabajos que tratan la relación entre el movimiento obrero y las fuerzas reaccionarias. Tres autores incluyeron las luchas 


\section{La lucha antifascista: hacia la politización reformista de la clase obrera. El caso entrerriano, 1931-1943.}

antifascistas en sus estudios: Matsushita (2014), Godio (1989) e Iñigo Carrera (2004, 2016). El trabajo del japonés Matsushita da cuenta de las perspectivas y discrepancias que tenían los socialistas y los sindicalistas en el seno de la CGT al respecto del fascismo y que facilitó la ruptura de 1935 (Matsushita 2014: 161-171). Algo similar hizo Julio Godio, aunque centrado en la situación del Partido Comunista (PC) y el viraje del Séptimo Congreso de la Internacional Comunista en 1935 y los cambios que la sección local del PC aplicó disciplinadamente tendientes a la conformación del Frente Popular (Godio 1989).

Por último, Nicolás Iñigo Carrera señala la conformación de una fuerza social a lo largo de la década del treinta. Esta mirada tiene un enfoque teleológico, en tanto concluye que la búsqueda de una integración al aparato del Estado y el reconocimiento de los derechos obreros concluiría su primera etapa en 1945 (Iñigo Carrera 2004:39). Partícipe de la tesis "continuista" omite que en la etapa formativa del peronismo se debió realizar un trabajo punitivo contra los mismos elementos que generaron la histórica huelga de 1936 (Torre 2011). En su última obra, muestra nuevos elementos históricos, anteriores a 1936, encabezados por los sectores revolucionarios del movimiento obrero. Afirma que la lucha contra el fascismo fue uno de los elementos que permitió romper el aislamiento de los sectores más radicalizados del movimiento obrero (Iñigo Carrera 2016: 287).

La historiografía provincial solo cuenta con dos trabajos donde se relacione la lucha antifascista. El primero se trata de Filiberto Reula (1971). La obra de Reula afirma que el radicalismo fue el principal actor en la lucha antifascista. La tesis de licenciatura de Clara Vuotto (2018), con un carácter más reciente, es la primera en analizar el movimiento obrero entrerriano en la lucha antifascista. La autora enmarca las prácticas antifascistas de la Federación Obrera Comarcal Entrerriana en la lucha contra la violencia estatal y paraestatal.

Desde nuestro ángulo pretendemos aportar pruebas empíricas sobre la formación de un cuerpo antifascista en la provincia de Entre Ríos compuesto por todas las tendencias de izquierda presentes en el territorio. Asimismo, intervenir en las discusiones sobre las transformaciones históricas de la conciencia de la clase trabajadora señalando la lucha antifascista como uno de los medios de la politización obrera que flexibilizó sus alianzas, favoreció el acercamiento con otras fuerzas obreras y confluyó, finalmente, con miembros de partidos patronales. Por lo tanto, la lucha antifascista, es un observable para considerar los procesos de integración al sistema social establecido y al desarrollo del reformismo obrero.

Para la reconstrucción histórica, trabajamos con una gran variedad de fuentes periodísticas de alcance local, provincial y nacional. También hemos utilizado fuentes del Archivo General de la Nación de los Fondos Documentales del Ministerio del Interior. 


\section{Rodolfo Leyes}

\section{1- Voz de alerta contra Uriburu, 1931-1932}

La provincia de Entre Ríos vivió una excepción durante el golpe de 1930 al no ser intervenida por el Poder Ejecutivo Nacional. El movimiento obrero, libre de fuertes represiones $^{1}$, aprovechó para lanzar una campaña en contra de Uriburu y la posibilidad de un fascismo "criollo"(Bisso 2007:36). Los comunistas de la provincia comenzaron una agitación contra su gobierno en el verano de 1931. Tildaban de fascista a Uriburu -también señalaban a Yrigoyen- e insistían en la necesidad de una huelga general revolucionaria. Si bien la represión alcanzó a estos militantes incluso algunos de ellos fueron enviados a Ushuaia- (Leyes 2018), el resto del movimiento obrero continuó realizando acciones en contra del presidente.

En octubre de aquel mismo año, la Unión Obrera Departamental de Concepción del Uruguay (UOD), realizó un gran mitin obrero contra la dictadura y solicitaron al presidente y al gobernador la vuelta a la normalidad constitucional, la derogación del Estado de Sitio y la Ley Marcial². Cuando Uriburu abandonó el poder en febrero del año siguiente, los sindicalistas publicaron una serie de comunicados en los cuales denunciaban que su gobierno representaba el renacer de los tiempos de Rosas y que se debía luchar por la libertad de quienes aún se encontraban en las "mazmorras carcelarias del capitalismo conservador y retrógrado por orden del tirano que se fue". Convocaron al pueblo a concurrir a un gran acto contra la dictadura a la que calificaban de fascista ${ }^{3}$. Luego de aquel acto, los miembros de la UOD elevaron una nota -rubricada por mil quinientos obreros- al Presidente Agustín P. Justo en solicitud de la libertad de los presos políticos, reapertura de los locales sindicales y estudiantiles, libertad de propaganda y disolución de la Legión Cívica4. En la localidad de Diamante también se realizó un acto de concurrencia masiva. Según los organizadores, participaron delegaciones de Concepción del Uruguay, Santa Fe y Paraná. Al igual que en Concepción del Uruguay, elevaron una nota al Presidente y pedían la vuelta del vapor "Chaco", que se dirigía a Europa con los deportados por Uriburu $^{5}$.

Este primer enfrentamiento contra las fuerzas reaccionarias giró en torno a la figura del presidente y a los peligros que gobiernos militares representaban para los trabajadores. A pesar de la concurrencia masiva, los actos aún no lograron conformar el frente antifascista que conoceremos más adelante, sino que se resumieron en un llamado en abstracto a un pueblo compuesto por trabajadores, estudiantes e intelectuales que se debía mantener en estado de alerta.

\footnotetext{
${ }^{1}$ El único caso que conocemos es el encarcelamiento del dirigente anarquista Ángel Borda, liberado luego por el gobernador Etchevehere. (Borda. 1987: 39-40)

2Periódico El Trabajo, Órgano de la seccional Concepción del Uruguay del Partido Socialista. Octubre de 1931.

${ }^{3}$ Los Principios, 27/02/1932.

${ }^{4}$ Los Principios, 29/02/1932.

${ }^{5}$ Los Principios, 08/03/1932.
} 


\section{La lucha antifascista: hacia la politización reformista de la clase obrera. El caso entrerriano, 1931-1943.}

\section{2-Sindicatos anti-fascistas y defensa de la libertad}

Este apartado versa sobre el modo en que los sindicatos encararon la lucha antifascista. En este sentido, queremos destacar que la organización gremial entrerriana estuvo hegemonizado antes del peronismo por el sindicalismo puro. Esa tendencia ideológica tuvo como marca la negación de la participación política, sin embargo, el propio desarrollo de la realidad los impulsó a lo largo de toda la década del treinta a tomar posición. Si bien no se constituyeron en partido electoral, a comienzos de la década del cuarenta, su alianza tácita con el radicalismo en el gobierno surgió públicamente. La aparición de las fuerzas reaccionarias llevó a los sindicatos enrolados en la Unión Obrera de la Provincia de Entre Ríos (UOPER) ${ }^{6}$ a tomar una posición activa frente aquellas organizaciones, lo cual se tradujo en su politización siempre tensionada por la idea de "apoliticismo" partidario. Por ello se esforzaron por enmarcar la lucha antifascista en la lucha sindical: "...el mejoramiento de los obreros en el terreno económico se trasuntan en una acción permanente en defensa de las libertades individuales y colectivas de los mismos, contraria siempre a los estados de reacción que vienen pregonando los grupos de la extrema derecha..."7.

La línea trazada en el Congreso fundacional de la UOPER en 1932 fue ratificada en el Primer Congreso extraordinario de 1935 cuando se discutió integrar un Frente Único con los partidos políticos, donde se afirmó que el arma para luchar contra la reacción era el sindicato. Por lo tanto, se debía extender la organización gremial para enfrentar a los fascistas ${ }^{8}$. A pesar de ello, la participación de los sindicatos como fuerzas antifascistas los empujó a la conformación de una alianza con otras fuerzas que plantearon el mismo tipo de lucha.

Durante 1933, la actividad mantiene elementos de continuidad con los actos contra Uriburu, lo que se define mejor es el enemigo contra el que se lucha y las alianzas con los partidos políticos. Ese año se inauguró un espacio antifascista en Concepción del Uruguay. En junio se realizaron actos en dicha ciudad, que tuvieron como escenario la plaza principal. El diario radical La Juventud señaló el éxito de la actividad que contó con oradores del PS, de la UCR y el referente de la UOD, Juan Balsechi ${ }^{9}$. También en la ciudad de Diamante se realizaron actos donde se denunciaron los crímenes fascistas y se dio "el toque de alerta frente al avance del

\footnotetext{
${ }^{6}$ La UOPER fue el principal agrupamiento de fuerzas obreras de la provincia de Entre Ríos, se logró a partir de la confluencia de dos corrientes de organización sindical que se vinieron gestando desde la década anterior: la corriente anarquista, con sede en Diamante y la corriente sindicalista pura con sede en Concepción del Uruguay. La corriente sindicalista siempre fue hegemónica dentro de aquella estructura y sobre todo luego de la expulsión de los anarquistas en 1935. Algo que está de algún modo implícito en el nombre mismo que adaptó la denominación departamental (UOD) por la provincial (UOP) (Gilbert y Balsechi 2008)

${ }^{7}$ El Despertar, Mayo de 1938.

${ }^{8}$ El Despertar, Septiembre de 1932. CGT, 12/04/1935.

${ }^{9}$ La Juventud, 10/06/1933.
} 


\section{Rodolfo Leyes}

fascismo y sus legiones armadas"10. La coincidencia de la agitación sindical en los dos centros de actividad gremial de la provincia da cuenta de la organización común de los actos.

A principios de 1934 se publican una serie de manifiestos que transparentaban la lucha antifascista. En enero, la UOD publicó un manifiesto contra las fuerzas de la reacción que, según ellos, financiaban la conformación de grupos de rompe-huelgas. Ellos como militantes gremiales no podían permitir el desarrollo de organizaciones que a rostro descubierto lucharan contra el gremialismo ${ }^{11}$. Tiempo después, los portuarios de Concepción del Uruguay, publicaron un comunicado donde declaraban el boicot a los productos de la granja San Marcelo, propiedad de Rodolfo Solanas Pacheco. Sus argumentos resaltaban que el propietario financiaba un sindicato amarillo y que como militante del Partido Demócrata Nacional (PDN), era simpatizante fascista ${ }^{12}$.

En octubre del mismo año El Tiempo publicó una proclama de la UOD de Concepción del Uruguay titulado "La palabra obrera contra la reacción fascista" en la cual daban cuenta de la actuación de las fuerzas reaccionarias, sus ataques a las comunidades judías y su oposición a la organización obrera. Esta proclama señalaba a los estancieros e industriales de la provincia como los "fascistas criollos"13. En diciembre se publicó un manifiesto más extenso en el periódico de la CGT. Plantearon que no se entendía cuál era el objeto de presentar a la provincia en un estado caótico por el solo hecho de que la UOPER realizaba una campaña para organizar y elevar la calidad de vida de los trabajadores. Afirmaron que la propia constitución provincial consideraba el bienestar de los trabajadores, la jornada legal de ocho horas y el pago en moneda nacional. Terminaban con la consigna: "A la violencia de los de arriba, sepamos contestarle con la más vigorosa y arrolladora acción de nuestras fuerzas sindicales (...) ¡Seamos enérgicos y fuertes soldados del gran ejército del trabajo!"14. A pesar del tono, no encontramos ninguna referencia a la conformación de milicias de autodefensa o similares; solo menciones de apoyo a la iniciativa manifestada por la CGT en caso de concretarse un cuerpo defensivo ${ }^{15}$. En octubre de 1936, se realizaron una serie de actos con participación de la UOD y la adhesión de varios partidos políticos contra la reacción. Consideraban que los reaccionarios proponían un sistema de fuerza y oprobio en beneficio del "alto

\footnotetext{
${ }^{10}$ El Debate, Gualeguay, 18/11/1933.

${ }^{11}$ La Vanguardia, 10/01/1934.

${ }^{12}$ La Vanguardia, 19/01/1934. La Vanguardia, 23/03/1934. Efectivamente, Solanos Pacheco fue presidente de un partido llamado Unión Cívica Nacionalista y fue investigado por la Comisión de Actividades Antiargentinas de la Cámara de Diputados de la Nación. Como resultado de esta investigación, fue procesado como simpatizante nazi en 1941, El Diario, Paraná, 22/08/1941. El Censor, Gualeguaychú, 29/08/1941. Dos años más tarde, sería designado como delegado por la Secretaria de Trabajo y Previsión a fines de 1943 por la revolución de Junio. Los Principios, 27/01/1943. El Litoral, Concordia, meses de noviembre-diciembre de 1943.

${ }^{13}$ El Tiempo, Paraná, 26/10/1934.

${ }^{14}$ CGT, 07/12/1934.

${ }^{15} C G T, 14 / 12 / 1934$. Al respecto de la reacción nacionalista contra la agitación sindical: CGT, 01/02/1935, CGT, 22/02/1935.
} 


\section{La lucha antifascista: hacia la politización reformista de la clase obrera. El caso entrerriano, 1931-1943.}

capitalismo imperialista"16. Días más tarde, se informó que las agrupaciones que respondían al "Frente Popular" (Sic) habían logrado un acto multitudinario con 2.000 participantes. Se había iniciado el acto con el canto del himno nacional argentino. El primero en hacer uso de la palabra fue el radical uruguayense Isidoro Neyra. También habló el radical Atanasio Eguiguren y el diputado nacional por el socialismo, Juan Antonio Solari. Juan Balsechi fue el orador designado por la UOD ${ }^{17}$. A fines de abril de 1938, con motivo del Tercer Congreso de la UOPER, se resolvió la creación de un organismo que “...agrupe a todas las fuerzas democráticas y liberales para combatir al fascismo y al nazismo. (...) El propósito de esta importante resolución, es agrupar a todas los elementos enemigos del fascismo de los diversos sectores de la opinión pública y sindical"18.

Por otra parte, las fuerzas sindicales entrerrianas participaron como aliados de las fuerzas republicanas y de izquierda durante la Guerra Civil española. A poco de conocerse el estallido de la guerra, Eduardo Pereyra, Secretario de la UOPER, envió un telegrama más en tono de apoyo republicano que revolucionario a sus pares de la Unión General de Trabajadores en Madrid: “... expresa amplia solidaridad en estos momentos de valiente lucha de proletariado y pueblo español para detener fuerzas reaccionarias que pretenden anular libertades y conquistas obrera. Pronto éxito y alcance total emancipación...".19 Además de telegramas y de las conocidas manifestaciones públicas, se lanzó un bono contribución para juntar dinero que fue despachado hacia la España republicana, que afirmaba: “...el triunfo del ejército leal, es el triunfo de la clase obrera del mundo contra la opresión y si el fascismo llegara a triunfar! Guay de los trabajadores organizados y de sus limitadas libertades sindicales!"20. Para fines de 1939, las acciones de finanzas que se realizaban tenían por finalidad enviar dinero a España para ayudar a los exiliados republicanos que habían sido derrotados. El día 4 de diciembre realizaron un pic-nic para reunir fondos e insistían: “Camaradas trabajadores, residentes españoles, pueblo de Uruguay: los trabajadores, el pueblo, los niños y ancianos de España republicana reclaman vuestra solidaridad; contribuid con vuestra presencia al éxito de este picnic en beneficio de todos ellos..."21.

La actividad antifascista estimuló los halagos de las esferas oficiales, que saludaron a los sindicatos por su compromiso con el régimen político:

"Se viene observando, en los últimos tiempos, la acción de las asociaciones gremiales argentinas en el sentido de aunar esfuerzos para defender las libertades democráticas públicas y privadas consagradas por nuestra organización jurídica constitucional. Se trata, como se ve, de una labor no habitual a los sindicatos (...) Comprenden los trabajadores

\footnotetext{
${ }^{16}$ La Juventud, 10/10/1936.

${ }^{17}$ La Juventud, 13/10/1936.

${ }^{18}$ El Despertar, Abril de 1938.

${ }^{19}$ El Debate, 04/08/1936.

${ }^{20}$ El Despertar, febrero de 1938.

${ }^{21}$ La Juventud, 22/11/1939. El llamado se amplió días más tarde: La Juventud, 28/11/1939.
} 


\title{
Rodolfo Leyes
}

argentinos que las aspiraciones de mejoramiento colectivo, la dignificación individual y la posibilidad de alcanzar cada día condiciones más justas de vida, sólo serán posibles dentro de un sistema jurídico inspirado en una concepción democrática del mundo y de la sociedad"22.

Para comienzos de los años cuarenta, con una década de cruces con las fuerzas de derechas, la pugna era cada vez más abierta. Cuando los conservadores del PDN de Concepción del Uruguay atacaron a la UOPER, los obreros entrerrianos llevaron su situación al Congreso de la Unión Sindical Argentina y este se pronunció contra los "pasquines nazi-fascistas":

\begin{abstract}
"Si la Unión Obrera Provincial ha tolerado en silencio hasta ahora tan canallesca campaña periodística, desde hoy declara que sabrá marcar a fuego a los enemigos declarados de la organización obrera, para que, como ciudadanos argentinos, sepan oportunamente darles el castigo que merecen, desalojándolos del escenario político de nuestra provincia"23.
\end{abstract}

Con los ánimos ya exacerbados, algunas semanas después, los conservadores prepararon un golpe encarcelando a Juan Balsechi24.

\section{3- Antifascismo y “Frente Popular”: los partidos políticos de izquierda}

En el apartado anterior destacamos la participación de los sindicalistas en las acciones antifascistas. Su concurrencia los obligó a buscar una alianza con los partidos políticos, especialmente con los socialistas y radicales. Aunque sus discursos y definiciones políticas no eran iguales, finalmente confluían en las mismas alianzas y métodos. Para los partidos políticos la lucha era de raíz democrático-republicana. Es decir, se defendía la tradición liberal ante el riesgo que conllevaba la victoria de las fuerzas contrarias a estos preceptos.

Bisso planteó la convivencia de dos discursos. Uno que reivindicaba la tradición del liberalismo argentino, en el que participaban fuerzas patronales progresistas y los socialistas. Y otro que tenía a los comunistas como sus voceros más fervientes. Estas líneas fueron denominadas por el autor como antifascismos tradicionalista y revolucionario, respectivamente (Bisso 2007:55). Sin embargo, la apelación a la tradición liberal fue la posición predominante. Los cambios de política de los comunistas y el creciente reformismo de los sindicalistas puros no dejaron portavoces de la posición revolucionaria.

Las primeras discusiones giraban en torno a los posicionamientos de los partidos nacionales frente a fenómenos internacionales, como el ascenso de los fascistas

\footnotetext{
${ }^{22}$ Provincia de Entre Ríos. Boletín del Departamento de Trabajo, septiembre de 1941, p. 1.

${ }^{23}$ Actualidad, Nogoyá, 24/02/1943.

${ }^{24}$ El Despertar, 18/03/1943. Los Principios, 18/03/1943.
} 


\section{La lucha antifascista: hacia la politización reformista de la clase obrera. El caso entrerriano, 1931-1943.}

italianos o lucha republicana en España ${ }^{25}$. Estas discusiones ayudaron a la formación incipiente de un cuerpo antifascista con carácter multipartidista. Un claro ejemplo de esta composición fue el Comité de Acción Antifascista de Concepción del Uruguay, fundado en junio de 1933 e integrado por militantes "de distintas ideologías cívicas", según declararon. Estos comités impulsaron actos por las ciudades más importantes de la provincia. En Concepción del Uruguay, el acto fue en la plaza principal de la ciudad y participaron diversos oradores: Alfredo Palacios y Mario Bravo del PS y Eduardo Laurencena, Ricardo Rojas y Ernesto Sanmartino por la UCR. También fueron invitados los sindicalistas de la UOD, a los que ya hicimos mención ${ }^{26}$.

En Paraná, un comité análogo realizó en junio de 1933 un acto al que concurrieron cerca de tres mil personas. Hablaron el diputado socialista Juan Nux, el director del diario radical El Tiempo, Silvano Santander, el socialista Elio Leyes y algunos estudiantes secundarios. Se destacó la intervención de Raúl Uranga, en aquel momento miembro del Partido Socialista Independiente ${ }^{27}$. Afirmó que la Legión Cívica estaba compuesta por "pitucos" de la calle Florida de Buenos Aires, y que si cien de estos elementos podían disolver una columna obrera, diez obreros armados eran capaces de darles una dura lección a cincuenta legionarios juntos. El discurso recibió grandes aplausos. Luego se realizó una marcha por el centro de Paraná ${ }^{28}$. Era la marcha más grande realizada contra el fascismo en el territorio provincial. Ese mismo día, pero en Concordia, el doctor Edgardo Bulnes dirigió un discurso de una hora y media en el Teatro Odeón: "Ni con Roma, ni con Moscú: América”, concluyó29. El diputado nacional por el socialismo, Juan Nux dijo que todos los problemas económicos que existían en el país debían ser solucionado con la cooperación de los partidos políticos para lograr así "el bienestar social de todos los habitantes, único medio de afianzar la democracia y establecer la libertad ciudadana sobre bases sólidas"30.

Luego del asesinato del diputado cordobés José Guevara en manos de legionarios, el PS se dio a la tarea de realizar una gran agitación por todo el país contra el fascismo. En la provincia de Entre Ríos, durante el mes de octubre, realizaron actos en cuatro localidades: Paraná, Basavilbaso, Nogoyá y La Paz. Los oradores fueron únicamente socialistas $^{31}$. En julio de 1934, se realizaron actos en Diamante contra los miembros de la Acción Nacionalista que, según se denunciaba, habían aprovechado el 25 de mayo para realizar un desfile. Participaron miembros de la UCR, los socialistas y los

\footnotetext{
25 Por ejemplo en 1932 se dieron actos en Paraná en apoyo al primer año de la república española con la presencia de socialistas y radicales. Diario La Acción, Paraná, 09/04/1932.

${ }^{26}$ El Debate, 03/06/1933 y 17/06/1933. La Juventud, 10/06/1933.

27Uranga se pasará a la UCR a mediados de los treinta, dará un fuerte impulso al Departamento Provincial del Trabajo y será uno de los más grandes referentes del radicalismo durante años hasta alcanzar la gobernación en 1958.

${ }^{28}$ El Tiempo, 02/06/1933.

${ }^{29}$ El Debate, Gualeguay, 03/06/1933.

${ }^{30}$ El Tiempo, 02/06/1933.

${ }^{31}$ El Tiempo, 13/10/1933.
} 


\section{Rodolfo Leyes}

gremios anarquistas de la ciudad ${ }^{32}$. Sin embargo, la suerte de Frente Único antifascista que se había formado en los primeros años de la década del `30 se fue desmembrando. La Vanguardia se refirió al abandono del Centro Socialista de Concepción del Uruguay y de los miembros de la UOD para no prestarse a las "maniobras de los comunistas"33.

En el contexto relativamente moderado de una provincia que no sufrió directamente los embates de las fuerzas reaccionarias, mantener una distancia con respecto a los comunistas era un ejercicio que todas las fuerzas practicaron. A mediados de la década de 1930 la acción de los comunistas estaba concentrada en unos pocos núcleos y con un peso importante en la comunidad de artistas y escritores vanguardistas (Leyes 2018). A partir de 1935 cuando la Internacional Comunista dictó una nueva línea de intervención, la formación de frentes populares antifascistas fue la prioridad ${ }^{34}$.

La idea de unidad de los sectores progresistas volvió al ruedo cuando estalló la Guerra Civil española. En este contexto, todos los partidos izquierda se inclinaron rápidamente a favor del bando republicano. Los socialistas de Concordia y los de Paraná organizaron un acto de solidaridad y colectas para los trabajadores españoles ${ }^{35}$. Incluso, llegaron a conformar en Paraná el comité de "Amigos de la República Española”, para divulgar la causa. Entre los oradores se encontraban radicales y socialistas. También se invitó a organizaciones estudiantiles, obreras y políticas ${ }^{36}$. Los socialistas obreros decían: "Si los partidos políticos son expresión de las clases sociales, necesariamente deberán seguir existiendo. Lo único posible en esta etapa de lucha contra la reacción y el fascismo es la unión para un objetivo común: Salvar la democracia"37.

Por su parte los comunistas anunciaban que en enero de 1936 realizarían su congreso provincial: “...tendrá como punto principal (...) la unidad de la juventud que piensa libremente para combatir ideas políticas exóticas y reaccionarias como es el fascismo y luchan por el afianzamiento de las instituciones populares"38. La prédica de los comunistas era sencilla: para detener el avance fascista había que formar un frente popular. Consideraban también que, en Entre Ríos, debía ser conducido por los radicales. En julio de 1937, con motivo de la visita del candidato a presidente Marcelo T. de Alvear a la provincia, los comunistas distribuyeron en Rosario del Tala un manifiesto de apoyo a Alvear que según ellos era garantía de libertades democráticas. Se posicionaron contra los monopolios y las minorías oligárquicas. Consideraban que solo un “...potente y amplio frente popular, será la fuerza de asegurar al pueblo argentino sus libertades democráticas y oponer un

\footnotetext{
${ }^{32}$ La Vanguardia, 07/07/1934.

${ }^{33}$ La Vanguardia, 22/07/1935.

34Partido Comunista. Esbozo de historia del Partido Comunista de la Argentina, Buenos Aires, Editorial Anteo, 1947, p.79.

${ }^{35}$ La Vanguardia, 22/08/1936. La Lucha, 10/09/1936. La Lucha, 20/10/1938.

${ }^{36}$ El Tiempo, 02/02/1937.

${ }^{37}$ La Lucha, 07/01/1938.

${ }^{38}$ El Debate, 09/01/1936.
} 


\section{La lucha antifascista: hacia la politización reformista de la clase obrera. El caso entrerriano, 1931-1943.}

dique a las hordas fascistas comandadas por Fresco y sus secuaces". El comunicado finalizaba con una reflexión acerca de los sucesos españoles, como muestra de lo que era capaz la reacción a la que el Frente Popular debía contraponerse para defender las "maltrechas" libertades democráticas: "La oligarquía, agente de los monopolios y sus sirvientes, las hordas del fascismo. La unión hará la fuerza de la democracia y la democracia salvará al país. Solidaridad con el heroico pueblo español" ${ }^{39}$

El último caso que analizaremos es el del pequeño Partido Socialista Obrero (PSO). Nacido de una expulsión del PS a mediados de los años treinta, el PSO intentó posicionarse más a la izquierda que su partido originario, esta tónica lo llevó a un acercamiento de facto con los comunistas. En un momento fue el socialismo mayoritario en la provincia de Entre Ríos, lo que nos habla por lo menos de un ambiente social que habilitaba un corrimiento a la izquierda de las fuerzas progresistas. Aunque, hacia los años cuarenta, su militancia iría mermando y sus cuadros pasarían al ostracismo, pues algunos de ellos volverían al PS o ingresarían al PC (Iñigo Carrera 2006).

Los miembros del PSO intentaron desarrollar un discurso más contestatario contra el imperialismo como principal enemigo, y contra la oligarquía que, según ellos, era su aliada nacional coaligada con sectores del fascismo local para facilitar el fraude. Creían al igual que los comunistas que solo un Frente Popular, encabezado por los radicales podía contener el avance de tales fuerzas ${ }^{40}$. Finalmente, toda su energía fue puesta en la intensión de crear este frente.

En 1936, los miembros del PSO fueron los principales propagandistas del acto en homenaje a Sáenz Peña -una suerte de reivindicación del voto- que concentraría a todas las fuerzas progresistas de Paraná. Desde los sindicatos, pasando por los estudiantes, partidos provinciales e incluso miembros del Partido DemócrataProgresista de Santa Fe se dieron cita allí. Los comunistas también estuvieron presentes, aunque no se les permitió el uso de la palabra ${ }^{41}$.

Durante el Primer Congreso provincial del PSO en febrero de 1938, se incluyó una resolución que denunciaba la actitud antidemocrática de "agentes a sueldo del hitlerismo alemán" junto a miembros del catolicismo entre los miembros de las colonias agrarias de origen germánico ${ }^{42}$. El nuevo partido que proponía un giro a la izquierda, terminó reclamando por la defensa de la democracia y la Constitución haciendo un llamado a los radicales. En este sentido se trató de una nueva sigla partidaria con la misma política que los otros dos partidos de izquierda.

El antifascismo en Entre Ríos tuvo un nuevo impulso llegada la década del cuarenta, cuando el fascismo tomó una nueva dimensión en la guerra más sangrienta que se vivió hasta el momento, la Segunda Guerra Mundial. Los socialistas en todo el país

\footnotetext{
${ }^{39}$ Información del Jefe del 12 Distrito de Correos y telégrafos al Presidente Justo, Paraná, 14/07/1937, en AGR-MI. S.VII. Fondo Agustín P. Justo. Caja No55, Doc. 82.

${ }^{40}$ Parte del Jefe de Correos y telégrafos al Presidente Justo, Gualeguaychú, 21/07/1937, en AGR-MI.

S.VII.FAPJ. Caja №55, Doc. № 95. El Tiempo, Paraná, 21/07/1937. La Lucha, 10/01/1938.

${ }^{41}$ La Lucha, 10/09/1936.

${ }^{42}$ La Lucha, 10/02/1938.
} 


\section{Rodolfo Leyes}

crearon una organización llamada Acción Argentina (Bisso 2005), que pronto reunió a parte de las fuerzas progresistas, menos a los comunistas locales que estaban inmovilizados por el pacto Nazi-Soviético. En julio de 1940 cuando se constituyó la delegación de la Acción Argentina en Villaguay declararon: "Por una patria grande, democrática, civilizada y justa, económicamente próspera y políticamente libre" 43 . Frente a las recurrentes negativas de los radicales a la unificación electoral, la Acción Argentina venía a institucionalizar una suerte de Frente Popular práctico dirigido contra las fuerzas fascistas. Llegó a poseer nueve filiales ${ }^{44}$ en toda la provincia (Bisso 2005: 351-357).

Como señalamos más arriba, las piezas se movían en dirección de una alianza, aunque la principal fuerza partidaria de la provincia -los radicales- se mostraran orgánicamente renuentes a aquella confluencia.

\section{4-1941, cohesión antifascista y dirección Radical}

El año 1941 marcó un cambio en la lucha antifascista de Entre Ríos a raíz de dos hechos ${ }^{45}$. El primero fue la reincorporación de los comunistas al bando antifascista por la ruptura del tratado de no agresión Nazi-Soviético. El segundo fue la llegada a la provincia de la Comisión Investigadora de Actividades Antiargentinas (CIAA) ${ }^{46}$. La incorporación de los comunistas a la lucha fue inmediata tras la invasión nazi a Rusia. Por ello, el partido convocó a las fuerzas democráticas contra el régimen fascista alemán y todos sus acólitos nacionales. El llamado se tradujo en varias tareas, como dar prensa a las nuevas organizaciones antifascistas que se iban creando, en especial si existía alguna mención a la invasión a la patria de los soviets. Por ejemplo, en Gualeguaychú se formó un Comité de Defensa de la Democracia dirigido por el presidente de la Cámara de Diputados provincial junto a otros diputados, miembros del Concejo Deliberante y de los sindicatos. Sobre esta unidad, los comunistas afirmaron que era uno de los hechos más auspiciosos y una prueba del compromiso con la causa antifascista ${ }^{47}$. En la misma línea, celebraron la realización de un acto democrático por parte de la UCR entrerriana, felicitaron la decisión y dieron su completo apoyo, al tiempo que llamaron a aplastar al "nazi-

\footnotetext{
${ }^{43}$ La Vanguardia, 02/07/1940.

${ }^{44}$ Las filiales eran: Basavilbaso, Colón, Concepción del Uruguay, Concordia, Chajarí, Villa Domínguez, Maciá, Paraná y Villaguay.

${ }^{45}$ Una muestra del estado de ánimo fue el debate que se concitó en torno a la prohibición de la proyección de la película El Gran Dictador de Charles Chaplin en enero de 1941, por la cual un intentó estallar una bomba en un cine de Gualeguaychú. Ver: La Juventud, 08/02/1941. El Censor, 10/02/1941.

${ }^{46}$ La Comisión Investigadora de Actividades Antiargentinas se conformó en 1941 designando al diputado radical Damonte Taborda, al diputado socialista Juan Solari y al diputado radical y entrerriano, Silvano Santander. El fin de la Comisión era investigar la existencia de infiltración "antiargentina". Específicamente, era una comisión que buscaba la existencia de acciones fascistas en todo el territorio nacional. Ver: República Argentina. Cámara de Diputados, Comisión Investigadora de Actividades Antiargentinas: Informes, Buenos Aires, Agosto y Septiembre, 1941.

${ }^{47}$ La Hora, 10/07/1941.
} 


\section{La lucha antifascista: hacia la politización reformista de la clase obrera. El caso entrerriano, 1931-1943.}

fascismo"48. Otro caso fue la constitución del "Comité de ayuda a los pueblos que luchan contra el nazifascismo" en Concepción del Uruguay, compuesto por la UOD, UCR, Comité de la Juventud Radical, Centro Socialista, PC, UOPER, ATE, Centro Social Israelita, Comité de defensa de la democracia, Comité de ayuda directa a las víctimas de guerra ${ }^{49}$.

Se organizaron actos en lugares alejados como San José de Feliciano, en los que participaban el PC coligados a la Acción Argentina ${ }^{50}$. Los reproches del diario conservador El Entre Ríos, no tardó en llegar. Aseveraban que la Acción Argentina había perdido toda seriedad y respeto, y que en un acto de Paraná, se había insistido en dar vivas a la URSS y al Comunismo. Reclamaban por la represión de sus actividades y la adhesión del gobierno de la provincia al decreto nacional contra las actividades de la Acción Argentina y del Frente Popular51. La constitución de este agrupamiento llamó la atención de uno de los diarios conservadores que aprovechó para cuestionar la composición de la alianza: “¿Cómo es posible, pués (Sic), que partidos argentinos admitan uniones con el comunismo?"52. En esta lucha local y por intermedio de las instituciones nacionales, los conservadores buscaron entorpecer el accionar propagandístico de la Acción Argentina. Por ejemplo, en diciembre de 1941, se quejaban los miembros de ésta, que no recibían las encomiendas ni los telegramas desde Buenos Aires y denunciaban que detrás estaba la mano del Poder Ejecutivo Nacional ${ }^{53}$.

El segundo hecho que agitó el ambiente fue el supuesto descubrimiento de un complot nazi en la provincia de Entre Ríos en agosto de 1941. La noticia tuvo fuerte repercusión mediática y dio muestras a los antifascistas de que el virus nazi estaba presente en el territorio provincial ${ }^{54}$. El órgano comunista La Hora se encargó de publicar la nómina de nombres de los supuestos complotados, sus localidades e incluso direcciones domiciliarias ${ }^{55}$. Por este hecho se llegó a encarcelar a cincuenta personas que fueron indagadas para esclarecer su relación con el complot. Había algunos curas, militares y hombres de negocios ${ }^{56}$.

A medida que los meses de agosto y septiembre fueron pasando, el saldo de presos implicados en el supuesto complot aumentó y la participación de la CIAA empeoró

\footnotetext{
${ }^{48}$ La Hora, 28/07/1941.

${ }^{49}$ La Hora, 06/10/1941. Resulta interesante que el único registro que tenemos de una reunión de organizaciones exclusivamente israelíes, se haya realizado en 1935 en la localidad de Basabilbaso, centro urbano con una de las mayores concentraciones de miembros de la comunidad judía. El hecho de que hayan abandonado esta política de distinción religiosa se debió probablemente a no quedar aislados por un lado y por otro, al peso de los miembros hebreos en organizaciones establecidas, como los partidos de izquierda. Periódico Sembrando, Basavilbaso, 01/06/1935, p.5.

${ }^{50}$ La Hora, 19/10/1941.

${ }^{51}$ El Entre Ríos, 04/12/1941. Sobre el acto mencionado: La Hora, 05/11/1941.

${ }^{52}$ El Censor, 08/09/1941. El Censor, 07/10/1941.

${ }^{53}$ La Hora, 02/12/1941.

${ }^{54}$ Ver El Diario de agosto y septiembre de 1941.

${ }^{55}$ La Hora, 04/08/1941. La lista es de más de cien individuos, mayoritariamente hombres y con una representación en todo el territorio provincial.

${ }^{56}$ El Diario, 02/09/1941. El Censor, 26/09/1941.
} 


\section{Rodolfo Leyes}

los ánimos. Finalmente, los informes hicieron menciones aisladas a las prácticas nazis en las escuelas confesionales y en algunos medios de prensa de la provincia, pero nada concreto ${ }^{57}$. Los conservadores argumentaron que el verdadero fin de la Comisión era la persecución política contra sus afiliados, a la par que se señaló que los radicales no atacaban a los verdaderos enemigos de la patria, los comunistas ${ }^{58}$. Como respuesta los radicales sacaron a relucir los casos de represión a los comunistas a fin de desmarcarse ${ }^{59}$. Incluso se llegó a interpelar al ministro de gobierno en la cámara de diputados provincial que determinó el alejamiento de Raúl Uranga, quién era presidente del Departamento Provincial de Trabajo ${ }^{60}$. Es sugerente que los radicales acusaron a los conservadores de apañar a nazis, y los conservadores respondieron que ellos lo hacían con los comunistas.

La formación del Frente Popular antifascista se iría constituyendo con todos sus elementos desde 1941. Podemos reconocer un año más tarde, en un acto realizado en Concepción del Uruguay, que conformación de aquel frente de facto estaba en marcha. Estuvieron presentes: Juventud Democrática, Raúl Uranga en representación de la UCR, PS, PC, Acción Argentina, Comité ayuda a los países democráticos, Junta de la Victoria, Centro de Empleados de Comercio, UOD y ATE ${ }^{61}$. Frente a este acto, los conservadores afirmaron: "El 'Frente Popular' entrerriano está, pués (Sic), en funciones. Los verdaderos argentinos, los que aman a su Dios y a la tradición nacional y a la verdadera democracia sabrán como oponerle valla"62.

El camino a la unidad democrática -como era denominada por los contemporáneoscontinuaba su desarrollo. En la antesala del golpe de 1943 se realizó una reunión del Consejo de la UOPER dónde manifestaron:

“...únicamente estableciéndose un Gobierno de un carácter democrático, podrán los trabajadores en general, conquistar el derecho de reunión, de prensa y palabra, porque viviendo bajo el imperio de la reacción, las organizaciones sindicales se ven trabadas en el libre juego de sus actividades, por tal razón exhorta a los sindicatos adheridos a que secunden todo movimiento e iniciativa tendiente a lograrla unidad de todas las fuerzas democráticas y liberales, con el propósito de luchar contra la reacción y el nazi-fascismo e imponer el verdadero régimen constitucional en nuestra República..."63

\footnotetext{
${ }^{57}$ Cfr.: Cámara de Diputados, Comisión Investigadora de Actividades Antiargentinas: Informes... Op. Cit. A pesar de la publicación de los cinco informes de la CIAA, la falta de estudios serios y amplios sobre la acción fascista en Entre Ríos no nos permite concluir que su presencia haya sido marginal. ${ }^{58}$ El Entre Ríos, 28/08/1941.

${ }^{59}$ El Diario, 29/08/1941.

${ }^{60}$ Entre Ríos, Diario de Sesiones de la Cámara de Diputados, Año 1941, 82ํㅜㄹoriodo Legislativo, Sesión del 26 de agosto de 1941, Paraná, Imprenta de la Provincia, 1941, pp. 130-132. Sobre el alejamiento de Uranga: El Censor, 04/09/1941.

${ }^{61}$ Los Principios, circa octubre 1942.

${ }^{62}$ El Entre Ríos, 01/10/1942.

${ }^{63}$ Unión Sindical, 31/05/1943.
} 


\section{La lucha antifascista: hacia la politización reformista de la clase obrera. El caso entrerriano, 1931-1943.}

Más de una década de luchas en común, acercamientos y reconfiguración de las políticas sectoriales se sintetizaron en 1943 en un llamado a la unidad por parte del grupo más renuente a entregar su lucha corporativa y autonómica, los sindicalistas puros de Concepción del Uruguay. Sin embargo, poco menos de un mes le duraría la posibilidad de política unitaria. Entre las primeras medidas de la Revolución de Junio estuvo la clausura de los sindicatos, de las organizaciones que luchaban por los aliados en la Segunda Guerra Mundial y se encarceló a sindicalistas y políticos de los diferentes partidos democráticos (Leyes 2017). Una verdadera década de cambios había unificado las alianzas que volverían a estar presente en 1946 bajo el nombre de Unión Democrática.

\section{5-La lucha antifascista como catalizador de la conciencia política}

Las clases sociales sufren transformaciones en su conciencia de la realidad. Dicha conciencia es tensionada por dos fuerzas: por un lado, la evolución de las fuerzas productivas y por otro, la lucha de clases. Por ello es que, si bien podemos establecer una división del grado de comprensión de la realidad, esta no se presenta linealmente, ni en un permanente ascenso. Sino, condicionada por el desarrollo de aquellas dos fuerzas indicadas. En este sentido, Gramsci planteó que las clases sociales son, en primera instancia, parte del sistema productivo pero sin ninguna identificación especial, pasan más adelante a una identificación económicocorporativa que tiene demandas de tipo económicas, hasta llegar a conformar una conciencia política de clase. Es decir, entiende cuáles son sus intereses materiales y busca discutir con el Estado la forma de cambiar la realidad y disputar espacios de poder: este es el pasaje al reformismo (Gramsci 2003: 51-62).

Más difícil es argumentar el conjunto de situaciones que posibilita el pasaje de un estado a otro. Consideramos que el reformismo obrero es aquella etapa en que se intenta modificar el Estado sin perder la autonomía como clase. En este proceso, los obreros morigeran sus demandas a cambio de obtener algunas mejoras secundarias de acuerdo a sus intereses. Así, admiten la representación burguesa e incluso de sus instituciones, al mismo tiempo la clase dominante deberá reconocer y ceder a las organizaciones obreras algunos de sus derechos.

Hiroshi Matsushita explicó que el motivo estructural del creciente reformismo obrero argentino de los años treinta fue la desocupación (Matsushita 2014: 374).

En efecto, el fenómeno de la desocupación obligó a los trabajadores a cambiar sus estrategias. Así fue que moderar las demandas y acomodarse al sistema social existente abrió un camino de resultados positivos para los obreros, pues reconocía la conformación de sindicatos y partidos políticos de izquierda comprometidos con la sociedad capitalista. Por esta vía el reformismo obrero se fue consolidando en el movimiento obrero pre-peronista. Sin embargo, la explicación de orden estructural no basta para explicar los cambios en las prácticas de los trabajadores. La crisis y la 


\section{Rodolfo Leyes}

desocupación acercaron los sindicatos al Estado, mientras la lucha antifascista fue uno de los caminos que los acercará al partido de gobierno y ahondará las relaciones con ellos.

Para las fuerzas de izquierda, el desarrollo del fascismo significaba el aniquilamiento de las libertades mínimas. Con este nuevo escenario de urgencia, quedó atrás la división tajante entre obreros y burgueses, a favor de un frente que defendía las libertades democrático-burguesas contra un enemigo único. El siguiente cuadro nos sirve para sintetizar las fuerzas, las acciones y las alianzas establecidas.

\begin{tabular}{|l|l|l|l|l|l|l|l|l|l|l|l|l|l|l|}
\hline \multicolumn{10}{|c|}{ Actos y mítines antifascistas en Entre Ríos divididos por fuerzas políticas y años, 1931- } \\
\hline & $\begin{array}{l}\mathbf{1 9 3} \\
\mathbf{1}\end{array}$ & $\begin{array}{l}\mathbf{1 9 3} \\
\mathbf{2}\end{array}$ & $\begin{array}{l}\mathbf{1 9 3} \\
\mathbf{3}\end{array}$ & $\begin{array}{l}\mathbf{1 9 3} \\
\mathbf{4}\end{array}$ & $\begin{array}{l}\mathbf{1 9 3} \\
\mathbf{5}\end{array}$ & $\begin{array}{l}\mathbf{1 9 3} \\
\mathbf{6}\end{array}$ & $\begin{array}{l}\mathbf{1 9 3} \\
\mathbf{7}\end{array}$ & $\begin{array}{l}\mathbf{1 9 3} \\
\mathbf{8}\end{array}$ & $\begin{array}{l}\mathbf{1 9 3} \\
\mathbf{9}\end{array}$ & $\begin{array}{l}\mathbf{1 9 4} \\
\mathbf{0}\end{array}$ & $\begin{array}{l}\mathbf{1 9 4} \\
\mathbf{1}\end{array}$ & $\begin{array}{l}\mathbf{1 9 4} \\
\mathbf{2}\end{array}$ & $\begin{array}{l}\mathbf{1 9} \\
\mathbf{4 3}\end{array}$ & $\begin{array}{l}\text { Tota } \\
\mathbf{1}\end{array}$ \\
\hline \begin{tabular}{l} 
Sindicatos \\
\hline
\end{tabular} & 2 & & & 1 & & & & 1 & & & & & 5 \\
\hline $\begin{array}{l}\text { Partido } \\
\text { Socialista }\end{array}$ & & & & 4 & & 2 & & 1 & & 1 & & & & 8 \\
\hline $\begin{array}{l}\text { Partido } \\
\text { Comunista }\end{array}$ & 1 & & & & & & & & & & & & & 1 \\
\hline $\begin{array}{l}\text { Sindicatos } \\
\text { y UCR }\end{array}$ & & & & & & & & & & & & & 1 & 1 \\
\hline $\begin{array}{l}\text { Partido } \\
\text { Comunista } \\
\text { y UCR }\end{array}$ & & & & & & & & & & & 1 & & & 1 \\
\hline $\begin{array}{l}\text { Todas las } \\
\text { fuerzas } \\
\text { junto a la } \\
\text { UCR }\end{array}$ & & & 4 & 1 & & 2 & & & & & 2 & 1 & & 10 \\
\hline Total & 3 & 2 & 4 & 5 & 1 & 4 & 0 & 1 & 1 & 1 & 3 & 1 & 1 & \\
\hline
\end{tabular}

La reconstrucción nos ofrece un total de 27 actos y mítines en más de diez localidades. La participación tuvo dos momentos de ascensos. El primero fue entre 1931-1934, teniendo el pico en $1933^{64}$. Impulsado al principio por los sindicatos y el Partido Comunista para luego tomar forma el frente popular antifascista. El segundo momento de agitación antifascista tiene un punto mínimo muy bajo pero se destaca el año 1941 como un retorno de la actividad comprendiendo el único caso de actividad en conjunto entre miembros de la UCR ${ }^{65}$ y el Partido Comunista. Este primer momento estuvo marcado por la denuncia contra el nazismo y el crecimiento de las organizaciones de derecha.

Del total de las acciones, se reconoce a los socialistas como la fuerza que mayor cantidad de acciones públicas realizaron, en particular durante 1934, año del asesinato del Diputado Guevara. Sin embargo, son las acciones en común entre

\footnotetext{
${ }^{64}$ Antes del año 1931 no se ha encontrado ningún tipo de acción antifascista dentro del territorio provincial.

${ }^{65} \mathrm{Se}$ ha considerado la presencia de la UCR no solo en los casos que el partido públicamente así lo dispuso, sino también en los casos donde reconocidos militantes de esa fuerza estuvieron presentes en las actividades.
} 


\section{La lucha antifascista: hacia la politización reformista de la clase obrera. El caso entrerriano, 1931-1943.}

varias fuerzas (diez acciones) las que prevalecieron durante toda la extensión del recorte.

La conclusión a la que debemos arribar por el cuadro es que el movimiento antifascista entrerriano tuvo su mayor impulso con la unificación de todas las fuerzas progresistas. Pero esta conclusión no agota la mirada sobre el proceso, sino que afirma lo que es nuestra principal hipótesis: la lucha antifascista acercó a las organizaciones en torno a un problema en común y esto facilitó la politización de espacios que eran renuentes a abandonar sus intereses corporativos, como los sindicatos, y apuntaló la formación de una alianza social que se tejía en torno al partido de gobierno, principal beneficiado de la nueva configuración.

\section{Conclusiones}

La aparición de fuerzas fascistas despertó un fuerte movimiento de repudio. En un comienzo, un conjunto de fuerzas de izquierdas y liberales fueron coincidiendo en la necesidad de combatir este nuevo movimiento que atentaba, potencialmente, contra las libertades conocidas. En este contexto, el antifascismo entrerriano fue parte de la corriente general de lucha en contra de la reacción que se desató en toda la Argentina.

Que se destaquen las actividades en las que participó todo el arco político de izquierda es el dato fundamental para comprender el tamaño del movimiento. Fue así que los sindicatos enrolados en la UOPER propusieron su participación en dicho movimiento a fin de defender las libertades sindicales, usando el espejo europeo para señalar las consecuencias del advenimiento de las fuerzas reaccionarias.

Algo análogo sucedió con los partidos políticos de izquierda, aunque hay que destacar que su posicionamiento fue abiertamente reformista desde un principio. Es decir, priorizaban la unificación de las fuerzas antifascistas en torno a la defensa de la democracia y la república, elemento propio de la línea política general del PS, pero que parecía alejado del discurso general del PSO. Por su parte, el PC tuvo una política que acompañó los movimientos de las directrices soviéticas. En un primer momento atacó a los radicales y a Yrigoyen, más tarde realizó llamados a la formación de un Frente Popular antifascista -en coincidencia con los otros partidos de izquierdapero en 1939, con la firma del Pacto Nazi-Soviético de no agresión, los comunistas se alejaron y pregonaron por la paz. En 1941, la invasión nazi a la Unión Soviética los trajo nuevamente al terreno del Frente Popular. Sin embargo, sus militantes siempre fueron tolerados con desconfianza por las demás fuerzas.

Los mayores beneficiarios de la disputa antifascista fueron los radicales. Todas las fuerzas -incluyendo a los sindicalistas hacía el final del periodo- solicitaron que sean ellos los organizadores del Frente Popular. Discursivamente, el llamado a los radicales, fue más mesurado y relacionado con la defensa de la democracia y la constitución. Se posponía la lucha revolucionaria a favor de la urgencia por defender 


\section{Rodolfo Leyes}

las libertades mínimas con una dirección burguesa. La falta de una definición política autónoma por parte de los partidos de izquierda y la adopción de la estrategia frentista por parte de los sindicatos facilitaron el puente con la burguesía y la integración a los intereses estatales.

Finalmente, podemos concluir que la lucha antifascista acercó a las fuerzas obreras al campo burgués por medio de alianzas con sectores patronales -en particular el oficialismo entrerriano- a los que instó a dirigir el movimiento en nombre de la democracia, la constitución y la república como valores supremos e inmediatos. En otros términos, sostenemos que la lucha antifascista fue el impulso al reformismo obrero que se desarrolló a lo largo de la década advirtiendo los peligros de las fuerzas reaccionarias que finalmente concretaron su golpe en 1943.

\section{Fuentes y referencias bibliográficas}

\section{Fuentes inéditas}

Información del Jefe del 12 Distrito de Correos y telégrafos al Presidente Justo, Paraná, 14/07/1937, en AGR-MI. S.VII. Fondo Agustín P. Justo. Caja №55, Doc. 82.

Parte del Jefe de Correos y telégrafos al Presidente Justo, Gualeguaychú, 21/07/1937, en AGR-MI. S.VII.FAPJ. Caja №55, Doc. № 95.

\section{Medios periodísticos}

Diario La Acción, Conservador, vinculado al episcopado de Paraná, Paraná.

Periódico Actualidad, UCR, Nogoyá.

Periódico El Censor, Partido Demócrata Nacional, Gualeguaychú.

Periódico El Debate, UCR, Gualeguay.

Periódico El Despertar, Órgano de la Unión Obrera de la Provincia de Entre Ríos, Concepción del Uruguay.

Periódico El Entre Ríos, Partido Demócrata Nacional, Colón.

Periódico El Litoral, Partido Demócrata Nacional, Concordia.

Periódico El Tiempo, UCR, Paraná.

Periódico El Trabajo, Órgano del Partido Socialista-Seccional Concepción del

Uruguay

Periódico La Juventud, UCR, Concepción del Uruguay.

Periódico La Vanguardia, Órgano del Partido Socialista, Buenos Aires.

Periódico Los Principios, UCR Concepción del Uruguay.

Periódico Sembrando, Basavilbaso. Órgano del Partido Socialista de Basavilbaso.

Provincia de Entre Ríos. Boletín del Departamento de Trabajo, septiembre de 1941.

Semanario CGT, Órgano de la Confederación General del Trabajo, Buenos Aires.

Semanario La Lucha, Órgano del Partido Socialista Obrero de Entre Ríos, Paraná.

Semanario Unión Sindical, Buenos Aires, Órgano de la Unión Sindical Argentina. 


\section{La lucha antifascista: hacia la politización reformista de la clase obrera. El caso entrerriano, 1931-1943.}

Semanario Unión Sindical, Órgano de la Unión Sindical Argentina, Buenos Aires. Vespertino El Diario, UCR, Paraná.

Entre Ríos, Diario de Sesiones de la Cámara de Diputados, Año 1941, 82 Periodo Legislativo, Sesión del 26 de agosto de 1941, Paraná, Imprenta de la Provincia, 1941.

\section{Referencias bibliográficas}

Argachá C. y Busiello 0. (2013). Nazismo y otros extremismos en Entre Ríos. Yusty: Concepción del Uruguay,.

Biasizo, R. (2008). Cambios estructurales en la economía de Entre Ríos, en el periodo de intervencionismo conservador, 1930-1945: la estrategia de agriculturación diversificada, como política del estado provincial, Ediciones Cooperativas: Buenos Aires.

Bisso A. (2005). Acción Argentina. Un antifascismo nacional en tiempos de guerra mundial. Buenos Aires: Prometeo Libros.

Bisso A. (Comp.) (2007). El antifascismo argentino. Buenos Aires: CeDInCI Editores.

Borda A. (1987). Perfil de un libertario. Reconstruir: Buenos Aires.

Casas S. (2006). "El antifascismo y la lucha política en la Argentina en el contexto de la Guerra Civil Española”, ponencia presentada en el Congreso Internacional La Guerra Civil Española 1936-1939, Sociedad Estatal de Conmemoraciones Culturales.

García Sebastiani (Ed.) (2006). Fascismo y antifascismo. Peronismo y antiperonismo. Conflictos políticos e ideológicos en la Argentina (1930-1955). Frankfurt-Madrid: Iberoamericana Vervuert.

Germani G. (1962). Política y sociedad en una época de transición. Buenos Aires: Paidos.

Gilbert J. \& Balsechi E. (2008). Voces del sindicalismo entrerriano: memorias de la Unión Obrera Departamental de Concepción del Uruguay, 1918-1943.Buenos Aires: Ediciones del zorrito.

Godio, J. (1989). El movimiento obrero argentino (1930-1943): Socialismo, comunismo y nacionalismo obrero. Legasa: Buenos Aires.

Gramsci A. (2003). Notas sobre Maquiavelo, sobre la política y sobre el Estado moderno. Buenos Aires: Ed. Nueva Visión.

Halperín Donghi, T. (2006). Argentina en el callejón. Ariel: Buenos Aires. 


\section{Rodolfo Leyes}

Hobsbawm E. (2005). Historia del Siglo XX, Buenos Aires: Crítica.

Iñigo Carrera, N. (2004). La estrategia de la clase obrera: 1936, Buenos Aires, Ediciones Madres de la Plaza de Mayo.

Iñigo Carrera, N. (2006). “Alternativas revolucionarias en los 30: la Alianza Obrera Spartacus y el Partido Socialista Obrero", en Bignani, H. y Roig, A. El pensamiento alternativo en la Argentina del siglo XX. Obrerismo, vanguardia, justicia social (19301960). Editorial Biblos: Buenos Aires.

Iñigo Carrera, N. (2016). La Otra estrategia. La voluntad revolucionaria (1930-1935), Imago Mundi: Buenos Aires.

Leyes, R. (2016). “Caravanas de hombres marchaban: El éxodo obrero en Entre Ríos. 1925-1945”, Folia Histórica del Nordeste, №27; Resistencia.

Leyes, R. (2017). “Represión a la izquierda en la provincia argentina de Entre Ríos durante la Revolución de Junio, 1943-1945”, Izquierdas, 32, marzo, Santiago de Chile.

Leyes, R. (2018). "Detrás de las crisis: Inversiones de capital, mecanización y desocupación en Entre Ríos, 1928-1946”, Revista Pampa, №17, Santa FeMontevideo.

Leyes, R. (2018). “Un espectro se cierne sobre Entre Ríos: una aproximación a la acción de los comunistas en la provincia, 1931-1943", Estudios Sociales, Vol. 55, Santa Fe, UNL, Segundo semestre.

Matsushita H. (2014). Movimiento obrero argentino, 1930-1945. Buenos Aires: Ediciones RyR.

McGee Deutsch, S. (2003). Contrarrevolución en la Argentina. La Liga Patriótica Argentina, 1900-1932. UNQ: Bernal.

McGee Deutsch, S.; Dolkart, R. H. (Ed.) (2001). La Derecha argentina. Nacionalistas, neoliberales, militares y clericales. Buenos Aires: Javier Vergara Editor.

Montenegro, S. (2002). La guerra civil española y la política argentina. Tesis de grado Doctor. Madrid: Universidad Complutense de Madrid.

Partido Comunista (1947). Esbozo de historia del Partido Comunista de la Argentina, Editorial Anteo: Buenos Aires.

República Argentina (1941). Cámara de Diputados, Comisión Investigadora de Actividades Antiargentinas: Informes, Buenos Aires, Agosto y Septiembre.

Reula F. (1971). Historia de Entre Ríos. Santa Fe: Editorial Castelvi.

Romero, J. L. (2005). Las ideas políticas en Argentina. FCE: Buenos Aires,. 
La lucha antifascista: hacia la politización reformista de la clase obrera. El caso entrerriano, 1931-1943.

Romero, J. L. (2011) “La Guerra Civil Española y la polarización ideológica y política: la Argentina 1936-1946”, Anuario Colombiano de historia social y de la cultura. Vol. 38 No. 2, Bogotá.

Torre, J. C. (2011). La vieja guardia sindical y Perón. Ediciones RyR: Buenos Aires.

Vuotto C. (2018). La acción directa, moneda corriente en la provincia. Prácticas libertarias en la Federación Obrera Comarcal Entrerriana (1932-1935). Tesis de Licenciatura de Historia. UADER-FHAyCS, Paraná.

Recibido: 04/02/2019

Evaluado: 31/03/2019

Versión Final: 17/04/2019 